\title{
The invasive species rules: competitive exclusion in forest avian mixed-species flocks in a fragmented landscape
}

\author{
Marcos Maldonado-Coelho, Miguel Ângelo Marini, Fábio Raposo do Amaral \& Rômulo Ribon
}

Here we correct a mistake introduced during the publishing process. The Figures A and B in Fig. 3 are out of order and the correct order is presented below.
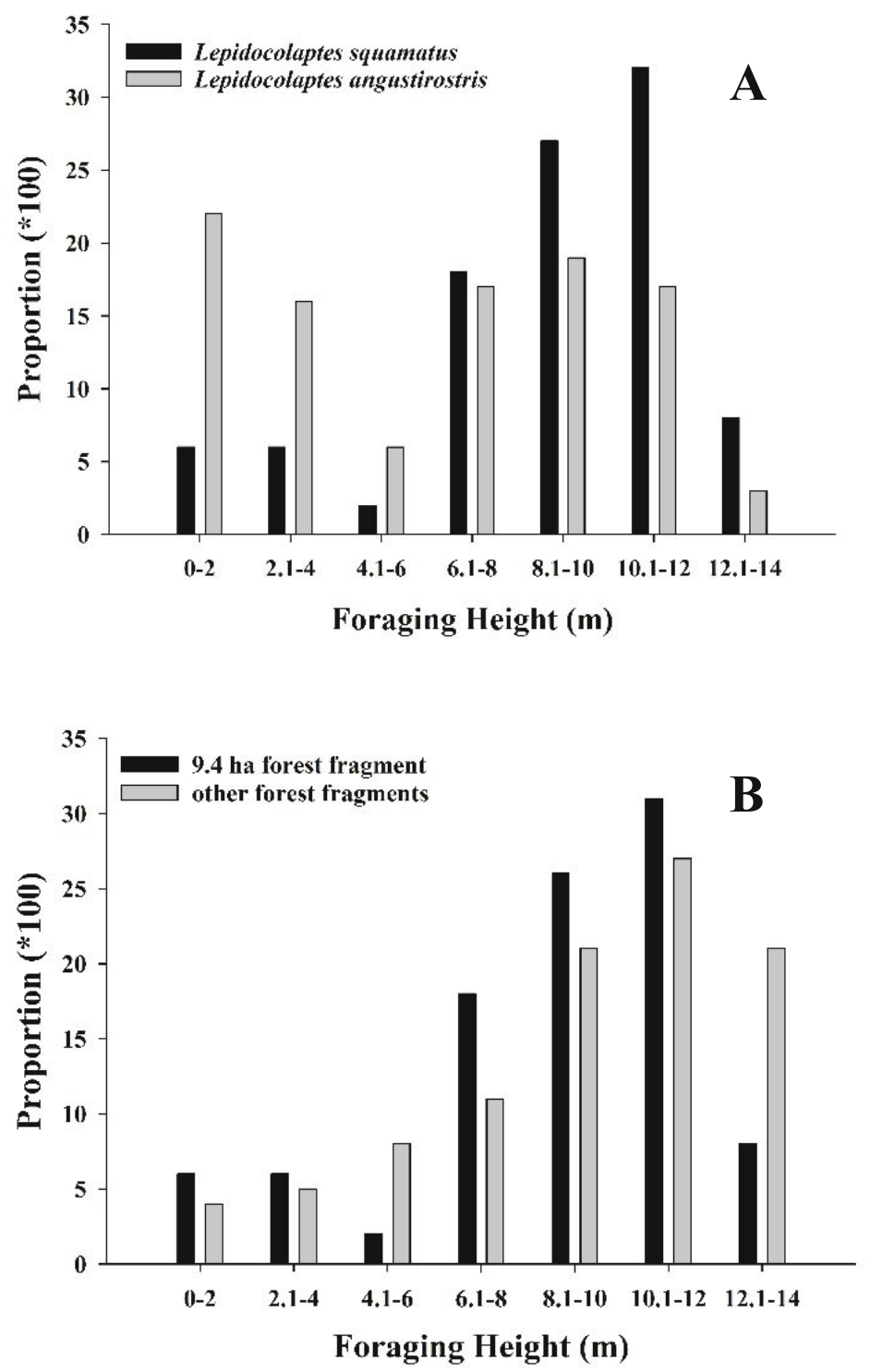

Figure 3. Proportion of foraging height distribution use for the two Lepidocolaptes species when associated with mixed-species flocks in the 9.4 ha forest fragment (A). Proportion of foraging height distribution use for the native woodcreeper (L. squamatus) individuals when associated with mixed-species flocks in the 9.4 ha forest fragment and for individuals of this species when associated with mixedspecies flocks in the other eight forest fragments $(\mathbf{B})$. 